\title{
The Influence of Tourism Image and Activities Appeal on Tourist Loyalty - A Study of Tainan City in Taiwan
}

\author{
Shwu-Ing $\mathrm{Wu}^{1} \&$ Yu-Hua Zheng ${ }^{1}$ \\ ${ }^{1}$ Department of Business Administration, National Chin-Yi University of Technology, Taichung, Taiwan, R.O.C. \\ Correspondence: Shwu-Ing Wu, Professor, Department of Business Administration, National Chin-Yi University of \\ Technology, No.57, Section 2, Zhongshan Road, Taiping, Taichung, Taiwan 41170, R.O.C.. Tel: 886-4-2392-4505. \\ E-mail: wusi@ncut.edu.tw
}

Received: October 22, 2014

Accepted: November 9, 2014

Online Published: November 12, 2014

doi:10.5430/jms.v5n4p121

URL: http://dx.doi.org/10.5430/jms.v5n4p121

\begin{abstract}
In recent years, local government authorities have been hosting impressive promotional events as a way of marketing local culture and creating commercial tourism opportunities. Using the Anping District of Tainan City as a case study, we explored the relationships among image, activity appeal, experiential value, satisfaction and loyalty, as well as compared groups with different travel frequencies.

Using convenience sampling, we conducted a questionnaire survey of subjects who had previously visited the Anping District, recovering a total of 831 valid questionnaires. We then categorized the subjects by travel frequency into highly frequent, moderately frequent, and infrequent visitors. Results showed that travel frequency affects relationships between variables: (1) the experiential value and satisfaction of infrequent visitors was more significantly influenced by image. (2) For moderately frequent visitors, experiential value had a stronger influence on satisfaction and activity appeal had a greater effect on loyalty. The results of this study can serve as reference in the planning of local tourism strategies.
\end{abstract}

Keywords: tourism image, activity appeal, experience value, satisfaction, loyalty

\section{Introduction}

Economic development has led to a significant rise in tourism and travel. Now the largest sector of international trade, tourism not only increases the "invisible output" of a country but can also generate revenue and benefit the local economy, as well as promote cultural exchange and facilitate greater understanding and collaboration between regions.

Most tourists select destinations based on image and attraction (Smith \& Colgate, 2007; Rudež, 2014). The impression that tourists have of a place reflects how they see its development and their experiences there (Hunt, 1975). Image is the sum of the beliefs, impressions, viewpoints and feelings that people have about certain objects, actions or events (Crompton, 1979). A unique image can attract tourists and make a positive impression on them. A recreational area or facility will be able to provide tourists with the benefits they expect as long as their priorities are consistent with those of their guests, making the destination more attractive (Mayo \& Jarvis, 1981). Image promotion can mould the opinions of tourists and leave them with a more positive impression. Tourists are motivated to travel partly due to the experiential value offered by the image of a destination (Baloglu \& McCleary, 1999). Wakefield, Blodgett, \& Sloan (1996) believed that the opinions of tourists regarding parking facilities, overall cleanliness, activities and food affect their willingness to revisit the place. This indicates that the experiential value provided to tourists influences their subsequent satisfaction with and willingness to revisit the destination.

Tourism attraction plays a major role in drawing travellers to a destination and is the basic motivation for visiting a place (Victor, 1989; Campo \& Alvarez, 2014). If the destination activities are attractive to tourists, they will have greater experiential value and be more willing to revisit. Smith \& Colgate (2007) indicated that experiential value can create appropriate sensory and emotional experiences for tourists, who identify first with their internal perception of the experience. Experiential value plays an intermediary role in the pursuit of satisfying experiences, affecting tourist contentment and loyalty. If customer satisfaction exceeds initial expectations, this influences their feelings about the place and their future behavioral intentions (Carpenter, 2009). In summary, image, activity appeal and 
experience are all closely linked.

Taking Tainan City in Taiwan as an example, the Tourism Bureau of the Tainan City Government (2012) boosted its tourism development by exercising creativity and recruiting industry partners to improve the quality of tourism in Tainan, attracting visitors from other regional areas. Offering unique historical sites, natural resources, ecology, tourism facilities and local delicacies, the Anping District of Tainan has great tourism potential. We therefore chose the Anping District as the subject of this research.

By studying travellers who had visited the Anping District, we sought to understand the image and attraction of the area to consumers, as well as their experiential value, satisfaction and loyalty levels, in order to further explore how image and activity appeal influence the tourist experience.

The main aim of this study was to explore how the image and activity appeal of the Anping District in Tainan affected the experiential value, satisfaction and loyalty levels of consumers. We surveyed travellers who had visited the area to build a relationship model and compare groups with different travelling frequencies.

\section{Literature Review}

\subsection{Tourism Image}

Image is an important representation of how tourists feel about a destination (Hunt, 1975; HU \& BAI, 2013). According to Crompton (1979), image refers to an individual's beliefs, thoughts and impressions about a location, and provides tourists with a certain feeling of anticipation (Fakeye \& Crompton, 1991). It also represents their expectations of a destination, which can motivate them to make a visit (Leisen, 2001).

Martin \& del Bosque (2008) categorized tourism image into five broad constructs: infrastructure and socioeconomic environment, atmosphere, natural environment, emotional image and cultural environment. Royo-Vela (2009) identified eight constructs of image: historical and cultural heritage, atmosphere, customer/guest services, architecture, art, shopping and dining, tourism management, supply and infrastructure. Fakeye \& Crompton (1991) categorized tourism image into social opportunities and attractions, nature and culture, accommodation and transport, infrastructure, food and friendliness, environment and recreational activities, and nightlife.

In reference to the above, we divided image into four categories, being ecology, culture and history, urban environment and local attractions, using these constructs to measure the tourism image presented by the Anping District of Tainan City.

\subsection{Activity Appeal}

According to Getz (1991), festivals or special events can be used to make a destination more appealing. Swarbrooke (2002) indicated that the attractiveness of an area derives from its holidays and events, such as sports competitions, art events, religious and folk festivals. Neirotti, Bosetti, \& Teed (2001) believed that the main elements that attract tourists are the excitement of competition, the appeal of international events, different cultural experiences, historical significance, lively ceremonies and educational experiences. According to William (1997), how appealing an activity is depends on its significance, the environment, and the relationship between the activity, society and culture.

In summary, unique local activities can attract large numbers of tourists. We chose festivals and group activities to measure the appeal of tourist activities in the Anping District.

\subsection{Experiential Value}

Experience, as interpreted by Kelly (1987), is the impression left after an event or after a period of time has passed. Tourism experience refers to the individual sensory, perceptual and behavioral interaction of a traveller engaging in an activity. Tourists do not focus only on emotions, commodities, services, novelty and fame, but ultimately emphasize enjoying the experience (Pine \& Gilmore, 2003). According to Schmitt (1999), tourists find experiential value through contact and interaction.

Sweeny \& Soutar (2001) categorized experiential value into feelings, society, price and quality, while Schmitt (1999) developed a set of scales to measure senses, emotions, thoughts, actions and relationships; this framework can be used to measure tourism experience.

Referring to the work of Sweeny \& Soutar (2001) and Schmitt(1999), this study identified emotional experience, sensory experience, and quality as the constructs of experiential value.

\subsection{Satisfaction}

Satisfaction, as defined by Dorfman (1979), is the subjective assessment of an activity or experience. Baker \& 
Crompton (2000) indicated that satisfaction is the real experience of an activity, the feelings left after interaction between the individual and the object. Reisinger \& Turner (2003) believed that satisfaction is the result of comparing pre-travel expectations with post-travel experiences.

According to Ennew \& Binks (1999), satisfaction is the feeling a tourist has about the overall product and services after interacting with service staff. Lee, Graefe \& Burns (2004) indicated that satisfaction should be measured as the level of overall happiness. Yoon \& Uysal (2005) countered that tourist satisfaction should be measured by comparing expected satisfaction levels, the value of the experience and previous travel experiences.

This study defined satisfaction as how travellers assess the overall sights and experiences of a destination, as measured against five constructs, being culture, scenery, friendliness, accuracy and overall satisfaction.

2.5 Loyalty

Chen \& Tsai (2007) defined loyalty as the willingness of tourists to revisit the place or recommend it to others. According to Kozak (2001), revisiting indicates that tourists are satisfied with a destination and willing to offer their continued business. Loyalty can be described as the strength of the relationship between individual attitude and revisiting (Dick \& Basu, 1994).

Yoon \& Uysal (2005) measured loyalty in relation to revisiting a place and recommending it to friends and family. In developing the constructs of consumer loyalty, Zeithaml, Berry, \& Parasuraman (1996) identified actions such as recommending products to others, informing others about the benefits of the product, encouraging friends and family to purchase the product, and re-purchasing the product. When measuring the post-purchase behavior of tourists, Bigne et al.(2001) studied customer response, recommendations and willingness to revisit. Cronin \& Taylor (1992) discussed the willingness of tourists to revisit a place and recommend it to others, measuring loyalty in accordance with willingness to revisit, promotion, recommendation and in-depth understanding.

Based on the concept presented by Cronin \& Taylor (1992), this study identified willingness to revisit and willingness to recommend a destination to others as the two constructs of loyalty.

\section{Research Hypotheses}

\subsection{Relationship between Image and Experiential Value}

According to Birgit (2001), image represents the expectations of tourists and is a major factor of consideration when they are choosing a destination. Tourists hope to gain experiential value from their travels, generating a positive impression. Their expectations are derived from their image of the place and their satisfaction with promotional activities, festivals and experiences. Pearce (1982) found that the image tourists have of a destination can change after their visit, meaning that tourists may come away with different impressions of the same place based on their different experiences.

Bigne et al. (2001) researched destination impression and perceived quality at two scenic coastal areas in Spain. They found that tourists rated destinations more highly if they were attracted to the image of the place, implying that an enhanced image increases experiential value (Fornell et al. 1996). Based on the above, tourism image has a positive effect on experiential value, which is our first hypothesis:

H1: The more attracted tourists are to the image of a destination, the higher their experiential value will be when visiting.

\subsection{Relationship between Activity appeal and Experiential Value}

Leiper (1990) believed that the appeal of tourism activities is a type of internal attraction that influences the behavior of tourists. Hu \& Ritchie (1993) indicated that activity appeal depends on the specific holiday requirements of travellers and their feelings and awareness of the potential satisfaction that the experience could provide.

In their research on the railway art village, Chen \& Yuan (2006) found that tourism attraction directly and positively influences perceived value. Ko \& Liu (2010) researched mainland Chinese tourists to Taiwan, and also found that attraction is positively correlated with experiential value, satisfaction and willingness to revisit. Based on the above, activity appeal positively affects experiential value, leading to the following hypothesis:

$\mathrm{H} 2$ : The more attractive the tourist activities of an area, the higher the experiential value gained by tourists to the area

\subsection{Relationship between Image and Satisfaction}

According to Bigne et al. (2001), the image of a destination positively affects satisfaction, willingness to revisit and 
willingness to provide recommendation. Other studies, such as that of Wang et al. (2009), have also shown that destination image affects the satisfaction of tourists. Bigne et al. (2001) found that image positively influences perceived satisfaction. However, in the research of Bosque \& Martin (2008) and Chen \& Tsai (2007), no significant relationship between image and satisfaction was demonstrated. With conflicting research results, this issue should be explored further. We propose the following hypothesis:

H3: The more tourists are attracted to the image of a destination, the more satisfied they will feel with their travels there.

\subsection{Relationship between Activity Appeal and Satisfaction}

The appeal of tourist activities is a kind of internal attraction that can affect behaviour (Leiper, 1990). According to Gunn (1988), attraction can draw people to an area or lead them to engage in certain activities. Hu \& Ritchie (1993) indicated that attraction affects how satisfied tourists are with a destination.

Ahmad (2012) pointed out that attraction contributes to satisfaction levels and word of mouth marketing; in other words, the attractiveness of an activity makes engagement more satisfying. When researching the relationships among the attraction of religious tourism, satisfaction and loyalty levels, Shen \& Hsieh (2003) found that attraction significantly and positively influences satisfaction levels. Based on the above, we propose the following hypothesis:

H4: The more attractive the recreational activities of an area, the more satisfied tourists will feel when visiting the area.

\subsection{Relationship between Image and Loyalty}

Image is an important deciding factor in whether tourists will travel to or revisit an area. The more positive the image, the more visitors prefer the area, drawing them to visit or revisit (Court \& Lupton, 1997; Li, 2013).

There is a positive relationship between image and intention to revisit (Bigne et al., 2001; Kim, Holland \& Han, 2013). Regardless of how satisfied a tourist feels, a positive image of the area could lead to him/her revisiting or recommending it to others. Therefore, the influence of image on loyalty must not be overlooked (Bosque \& Martin, 2008). Bosque \& Martin (2008) and Yoon \& Uysal, (2005) found a positive relationship between image and loyalty. Bigne et al. (2001) also believed that the image of a tourist destination positively affects the willingness of travellers to revisit or recommend the place.

In surveying the international tourism image of Thailand, Rittichainuwat, Qu \& Brown (2001) found that the more positive the image, the more willing tourists were to revisit. According to Bigne et al. (2001), tourism image positively influences perception, satisfaction, willingness to revisit and willingness to recommend. Based on the above, we propose the following hypothesis:

H5: The more positively tourists feel about the image of a destination, the more loyal they will be to this locality

\subsection{Relationship between Activity Appeal and Loyalty}

Attraction is strongly correlated with and affects willingness to revisit. Greater attraction implies greater willingness to revisit (Liu, Tsou \& Ting, 2011). Ahmad (2012) pointed out that attraction contributes to satisfaction levels and word of mouth marketing; in other words, the attractiveness factor increases consumer loyalty. Researching tourism attraction, service quality, perceived value, customer satisfaction and loyalty levels, Li \& Chen, (2009) found that attraction directly and positively affects perceived value and loyalty. In researching the Kaohsiung International Container Arts Festival, Chen \& Lee (2006) found that overall attraction is significantly correlated with willingness to revisit. In their study of religious activities, Shen \& Hsieh (2003) found that activity appeal significantly and positively influenced the loyalty of tourists. Based on the above, we propose the following hypothesis:

H6: The more appealing the tourist activities of an area, the more loyal tourists will be to this area

\subsection{Relationship between Experiential Value and Satisfaction}

According to Bolton \& Drew (1991), experiential value positively influences customer satisfaction. Lee, Lee \& Wicks (2004) believed that any type of experiential value, regardless of its form, has a positive effect on customer satisfaction levels. Ross (1993) indicated that when tourists have a better experience than expected, they are more satisfied and more willing to revisit the area. In the view of Oliver (1993), the emotional experience of consumers positively affects their satisfaction levels. Pine \& Gilmore (1998) found that experiential value has a significant and positive relationship with customer satisfaction and loyalty. Experiential value directly or indirectly affects satisfaction and willingness to revisit, leading tourists to recognize how much they enjoyed the experience (Kim, Holland \& Han, 2013). In summary, experiential value positively affects satisfaction levels. We propose the 
following hypothesis:

H7: The greater the experiential value offered by an area, the more satisfied tourists will feel.

\subsection{Relationship between Satisfaction and Loyalty}

Satisfaction levels are important to determine because they are closely related to loyalty levels (Oliver, 1999). Some studies have shown that satisfaction positively influences loyalty (Bosque \& Martin, 2008 and Yoon \& Uysal, 2005).

According to Fornell (1992), satisfaction positively influences loyalty and satisfied customers spread positive word of mouth. Kotler et al. (1996) also described a positive causal relationship between image $\rightarrow$ service quality $\rightarrow$ satisfaction $\rightarrow$ post-purchase behaviour. In summary, satisfaction positively affects loyalty, leading us to the following hypothesis:

H8: The more satisfied tourists are with an area, the more loyal they will be to the area.

\subsection{Comparing Groups with Different Travel Frequencies}

The tourism market is often categorized according to travel habits, frequency of travel and loyalty. Mullin (1985) proposed the basis of the sports participation frequency theory, categorizing consumers by their average number of bowling games per month into high level consumers, moderate consumer, and low consumers. Liu (2009) also categorized tourists by loyalty into three groups (high, moderate and low loyalty) in order to map out the handicrafts consumer market. Birgit (2001) divided tourists by destination image, to identify the target market of advertisers and their demographics and characteristics, using this information to develop marketing strategies.

This study categorized the market based on travel frequency, in order to analyze how travel frequency affects the relationship between tourism image, attraction, and experience.

H9: Groups with different travel frequencies show significant differences in the intensity of construct relationships.

\section{Research Design}

\subsection{Research Framework}

The independent variables were the four constructs of image (natural ecology, culture and history, urban environment and local features) and the two constructs of attractions (festivals and group activities). We discussed how image and activity appeal affect experiential value, satisfaction and loyalty.

Based on the literature review, we established hypotheses and developed a research structure, then designed a questionnaire and conducted a sample survey to verify the hypotheses, exploring the relationships and extent of influence between each variable, as well as comparing groups with different travel frequencies. The research framework is illustrated in Figure 1.

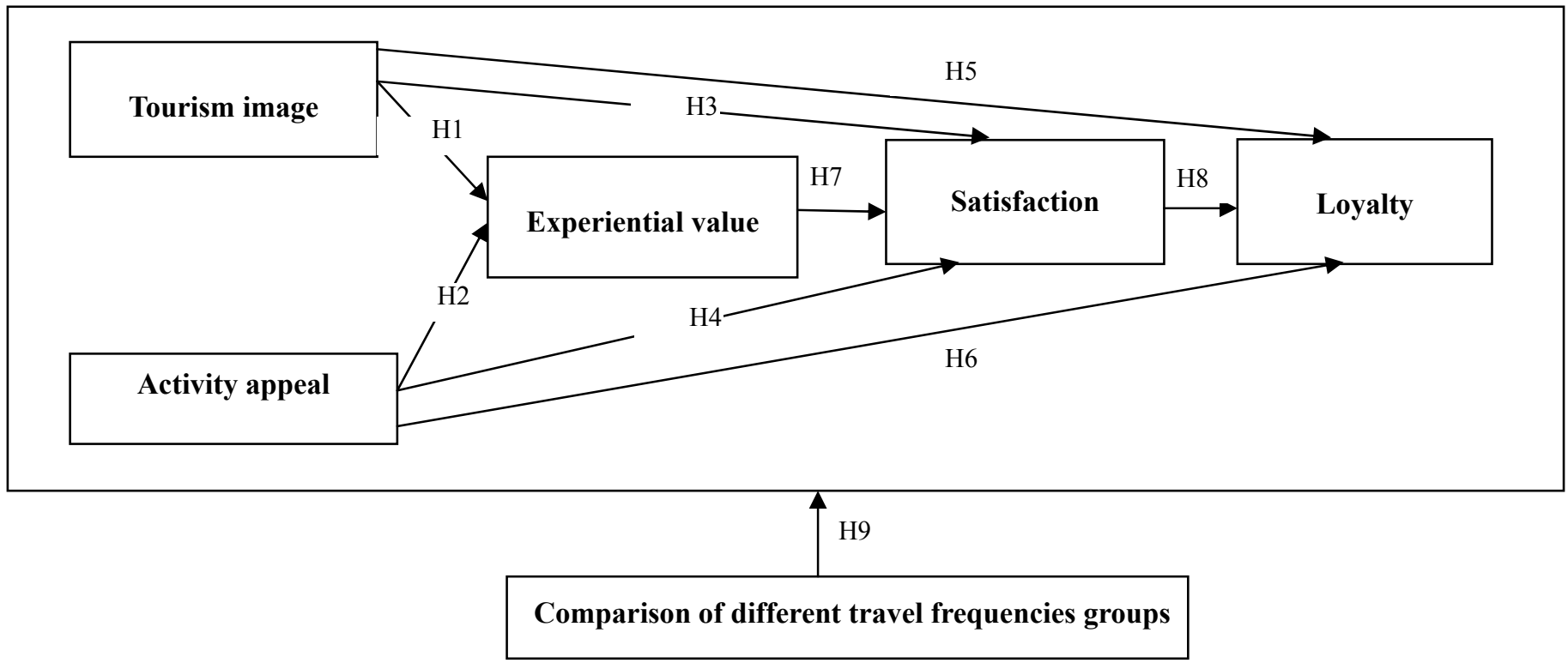

Figure 1. Research framework 


\subsection{Research Variables}

This study first designed a draft questionnaire based on the literature and theories reviewed above, aiming to understand how image and activity appeal influence experiential value, satisfaction and loyalty in the Anping District. We first conducted personal interviews to gather data on how previous visitors to Anping felt about the area and their post-visit behaviour. The questionnaire comprised six sections, with the first five employing a 7-point Likert scale ranging from "strongly disagree" to "strongly agree". A nominal scale was used in the sixth section to measure responses.

\subsection{Sampling Design}

We sampled tourists who had previously visited the Anping District. To maximize the number of valid questionnaires recovered, subjects were required to be at least 15 years of age. Convenience sampling was used as staff members distributed the questionnaires over a period of three months, from 16 May to 16 August 2013.

\subsection{Pilot Testing and Pre-testing}

To ensure that the questionnaire would be an effective instrument of measurement, we conducted pilot testing and pre testing, and modified the questionnaire before conducting the formal survey. For the pilot test, convenience sampling was employed to select 30 subjects who had visited the Anping District. As results showed that the meaning of the questions were unclear, we modified the wording or added further explanation.

Using convenience sampling, we then selected another 100 subjects for pre-testing of the modified questionnaire, and tested the reliability and validity of the data. Results showed that the Cronbach's $\alpha$ of each construct ranged from 0.833 to 0.922 , meeting the $>0.7$ standard and indicating that each construct was reliable (Nunnally, 1978). According to the results of factor analysis, the eigenvalue of each construct exceeded 1 and the cumulative explained variance exceeded 0.5 . The factor loading of each variable, as well as the item-total correlation coefficients, all came within reach of or exceeded 0.5, demonstrating the convergent validity of each construct (Kerlinger, 1978; Kaiser, 1958).

\section{Results}

\subsection{Sample Structure}

Our subjects were individuals who had previously visited the Anping District. We distributed a total of 850 questionnaires using convenience sampling, from which 831 valid questionnaires were recovered after discarding the invalid 19 , resulting in a recovery rate of $97.8 \%$.

As far as demographics, $53.9 \%$ of samples were female; the $25-34$ age bracket was the largest, at $36.7 \%$, followed by the $15-24$ bracket at $32.3 \% ; 34.4 \%$ of subjects resided in south Taiwan and a majority had a university or college level of education (64.0\%), followed by high school education $22.4 \%$. With regard to occupation, students made up the largest group at $26.4 \%$, followed by those employed in the service industry at $24.7 \%$. As far as average monthly income or disposable income, $40.9 \%$ of respondents fell into the NTD10,000-30,000 category, followed by $24.2 \%$ in the NTD30,001-50,000 category. On average, $33.8 \%$ of respondents visited the area every six months or less, while $32.7 \%$ visited every year.

\subsection{Reliability and Validity Analysis of the Formal Survey}

After the formal survey had been completed, we analysed the reliability and validity of each construct. According to Nunnally (1978), reliability is considered high if Cronbach's $\alpha$ exceeds 0.7 , and Kerlinger (1978) stated that item to total correlation must exceed 0.5 . The Cronbach's $\alpha$ and item to total correlation of each construct satisfied the criteria above, demonstrating strong overall reliability. The composite reliability (CR) of each construct and factor ranged from 0.898 to 0.946 , exceeding 0.7 and indicating high internal consistency. The average variance extracted (AVE) of the latent variables ranged from 0.659 to 0.853 , meeting the $>0.5$ standard and indicating that the measurement items within each construct are highly consistent (for further details see Table 1).

We employed factor analysis to test the convergent validity of the questionnaire. The criteria established by Kaiser (1958) are the eigenvalue of extracted factors $>1$, the factor loading of each construct variable $>0.5$, and cumulative explained variation $>0.5$. The results for each construct in this study were close to or greater than these values, indicating an acceptable level of convergent validity.

We also conducted correlation analysis to test the discriminant validity of each construct based on the recommendations of Gaski \& Nevin (1985), who suggested that the correlation between any two constructs should be less than the Cronbach's $\alpha$ of the individual construct. Results verified that the correlations between all constructs 
met the above criteria, indicating satisfactory discriminant validity.

Table 1. Reliability and validity analysis for formal survey

\begin{tabular}{|c|c|c|c|c|c|c|c|}
\hline Variable & $\begin{array}{l}\text { Item to total } \\
\text { correlation }\end{array}$ & $\begin{array}{l}\text { Factor } \\
\text { loading }\end{array}$ & Eigenvalues & $\begin{array}{c}\text { Cumulative } \\
\text { explained } \\
\text { variance\% }\end{array}$ & $\begin{array}{c}\text { Cronbach's } \\
\alpha\end{array}$ & $\begin{array}{l}\text { Composite } \\
\text { reliability } \\
\text { (CR.) }\end{array}$ & $\begin{array}{c}\text { Average } \\
\text { extracted } \\
\text { variance } \\
\text { (AVE) }\end{array}$ \\
\hline \multicolumn{8}{|c|}{ Tourism image } \\
\hline \multicolumn{8}{|c|}{ Natural ecology } \\
\hline Beautiful harbour & 0.759 & 0.862 & \multirow{5}{*}{3.373} & \multirow{5}{*}{67.456} & \multirow{5}{*}{0.878} & \multirow{5}{*}{0.912} & \multirow{5}{*}{0.674} \\
\hline Lots of beautiful scenery & 0.794 & 0.885 & & & & & \\
\hline Pleasant climate & 0.627 & 0.753 & & & & & \\
\hline Unique sights & 0.706 & 0.818 & & & & & \\
\hline Well-preserved environment & 0.657 & 0.780 & & & & & \\
\hline \multicolumn{8}{|c|}{ Culture and history } \\
\hline Historically significant laneways & 0.706 & 0.856 & \multirow{4}{*}{2.746} & \multirow{4}{*}{68.650} & \multirow{4}{*}{0.847} & \multirow{4}{*}{0.898} & \multirow{4}{*}{0.687} \\
\hline Heritage sites & 0.712 & 0.859 & & & & & \\
\hline $\begin{array}{l}\text { Detailed and compressive historical } \\
\text { records }\end{array}$ & 0.689 & 0.827 & & & & & \\
\hline Famous folk religion attractions & 0.614 & 0.770 & & & & & \\
\hline \multicolumn{8}{|c|}{ Urban environment } \\
\hline Convenient transportation & 0.770 & 0.842 & \multirow{7}{*}{4.619} & \multirow{7}{*}{65.981} & \multirow{7}{*}{0.913} & \multirow{7}{*}{0.931} & \multirow{7}{*}{0.659} \\
\hline Wide range of dining choices & 0.678 & 0.766 & & & & & \\
\hline Easy accommodation & 0.776 & 0.847 & & & & & \\
\hline Complete public facilities & 0.619 & 0.711 & & & & & \\
\hline Well-planned roads & 0.830 & 0.885 & & & & & \\
\hline Convenient parking & 0.712 & 0.797 & & & & & \\
\hline Clear road markings and signs & 0.749 & 0.824 & & & & & \\
\hline \multicolumn{8}{|c|}{ Local specialities } \\
\hline $\begin{array}{l}\text { Traditional businesses and } \\
\text { stores }\end{array}$ & 0.738 & 0.843 & \multirow{5}{*}{3.558} & \multirow{5}{*}{71.156} & \multirow{5}{*}{0.898} & \multirow{5}{*}{0.925} & \multirow{5}{*}{0.712} \\
\hline Unique souvenirs & 0.783 & 0.874 & & & & & \\
\hline Diverse local foods & 0.745 & 0.842 & & & & & \\
\hline Exotic dining & 0.813 & 0.891 & & & & & \\
\hline Special mementos & 0.648 & 0.763 & & & & & \\
\hline \multicolumn{8}{|c|}{ Activity appeal } \\
\hline \multicolumn{8}{|c|}{ Local holidays and festivals } \\
\hline $\begin{array}{l}\text { Artistic events (such as arts and } \\
\text { culture exhibitions and fairs) } \\
\text { would attract me to Anping }\end{array}$ & 0.691 & 0.828 & 2.837 & 70.937 & 0.863 & 0.907 & 0.709 \\
\hline Performing events (such as fire & 0.747 & 0.871 & & & & & \\
\hline
\end{tabular}




\begin{tabular}{llll}
\hline $\begin{array}{l}\text { dancing and opera) would } \\
\text { attract me to Anping }\end{array}$ & & \\
\hline $\begin{array}{l}\text { Entertainment events (such as } \\
\text { shopping area and food }\end{array}$ & & \\
festivals) would attract me to & 0.753 & 0.873 \\
Anping & & \\
Sporting events (such as dragon & & \\
boat races) would attract me to & 0.646 & 0.794 \\
Anping
\end{tabular}

Anping

\section{Group activities}

Academic events (such as conferences and camping services) would attract me to $0.765 \quad 0.870$

Anping

Arts events (such as musical events or dance performances) would attract me to Anping Social events (such as summer camps or interscholastic activities) would attract me to

$\begin{array}{ll}0.780 & 0.879\end{array}$

Anping

Fitness events (such as volley ball and outdoor games) would attract me to Anping

\begin{tabular}{|c|c|c|c|c|c|c|c|}
\hline \multicolumn{8}{|c|}{ Experiential value } \\
\hline \multicolumn{8}{|c|}{ Emotional experience } \\
\hline Helps me relieve stress & 0.804 & 0.880 & \multirow{5}{*}{3.879} & \multirow{5}{*}{77.570} & \multirow{5}{*}{0.927} & \multirow{5}{*}{0.945} & \multirow{5}{*}{0.776} \\
\hline Cheers me up & 0.876 & 0.928 & & & & & \\
\hline Relaxes me & 0.859 & 0.916 & & & & & \\
\hline Friendly and intimate & 0.766 & 0.847 & & & & & \\
\hline $\begin{array}{l}\text { The atmosphere satisfies me as } \\
\text { a tourist }\end{array}$ & 0.740 & 0.829 & & & & & \\
\hline \multicolumn{8}{|c|}{ Sensory experience } \\
\hline $\begin{array}{l}\text { I can get to know the local culture } \\
\text { and customs }\end{array}$ & 0.774 & 0.860 & \multirow{5}{*}{3.526} & \multirow{5}{*}{70.513} & \multirow{5}{*}{0.895} & \multirow{5}{*}{0.923} & \multirow{5}{*}{0.705} \\
\hline I can enjoy beautiful nature & 0.661 & 0.774 & & & & & \\
\hline $\begin{array}{l}\text { I can learn about local history and } \\
\text { heritage }\end{array}$ & 0.781 & 0.870 & & & & & \\
\hline I can enjoy unique local foods & 0.719 & 0.828 & & & & & \\
\hline $\begin{array}{l}\text { I can enjoy a feeling of tradition } \\
\text { and nostalgia }\end{array}$ & 0.769 & 0.863 & & & & & \\
\hline \multicolumn{8}{|c|}{ Experiencing quality } \\
\hline Heritage sites are well preserved & 0.656 & 0.791 & \multirow{4}{*}{3.063} & \multirow{4}{*}{76.585} & \multirow{4}{*}{0.897} & \multirow{4}{*}{0.929} & \multirow{4}{*}{0.766} \\
\hline $\begin{array}{l}\text { Travel environment is orderly and } \\
\text { clean }\end{array}$ & 0.853 & 0.924 & & & & & \\
\hline Food is safe and hygienic & 0.817 & 0.902 & & & & & \\
\hline Roads are well maintained & 0.777 & 0.877 & & & & & \\
\hline \multicolumn{8}{|c|}{ Satisfaction } \\
\hline Rich cultural resources & 0.702 & 0.795 & \multirow{4}{*}{4.213} & \multirow{4}{*}{70.222} & \multirow{4}{*}{0.915} & \multirow{4}{*}{0.934} & \multirow{4}{*}{0.702} \\
\hline $\begin{array}{l}\text { I have happy memories of my } \\
\text { travels there }\end{array}$ & 0.744 & 0.827 & & & & & \\
\hline The locals made me feel welcome & 0.756 & 0.836 & & & & & \\
\hline I was provided with travel & 0.747 & 0.825 & & & & & \\
\hline
\end{tabular}

$\begin{array}{lllll}3.082 & 77.051 & 0.901 & 0.931 & 0.771\end{array}$

$0.793 \quad 0.888$

$0.772 \quad 0.874$

\section{Experiential value}

Emotional experience 


\begin{tabular}{|c|c|c|c|c|c|c|c|}
\hline \multicolumn{3}{|l|}{ information services } & & & & & \\
\hline $\begin{array}{l}\text { I was very satisfied with the } \\
\text { overall cleanliness }\end{array}$ & 0.791 & 0.859 & & & & & \\
\hline $\begin{array}{l}\text { I was very satisfied with the } \\
\text { overall quality of service }\end{array}$ & 0.825 & 0.882 & & & & & \\
\hline \multicolumn{8}{|c|}{ Loyalty } \\
\hline $\begin{array}{l}\text { I am very willing to make another } \\
\text { trip to Anping }\end{array}$ & 0.797 & 0.909 & \multirow{3}{*}{2.557} & \multirow{3}{*}{85.235} & \multirow{3}{*}{0.913} & \multirow{3}{*}{0.946} & \multirow{3}{*}{0.853} \\
\hline $\begin{array}{l}\text { I will recommend Anping as a } \\
\text { travel destination to my family } \\
\text { and friends }\end{array}$ & 0.879 & 0.950 & & & & & \\
\hline $\begin{array}{l}\text { I will tell others about the } \\
\text { attractions of Anping }\end{array}$ & 0.801 & 0.911 & & & & & \\
\hline
\end{tabular}

\subsection{Confirmatory Factor Analysis}

We employed AMOS software to conduct confirmatory factor analysis (CFA) of the measurement models for tourism image, activity appeal, experiential value, satisfaction and loyalty. Construct validity was measured according to rigorous principles: for fit indices, the ratio between the chi-squared value and degrees of freedom must not exceed 3 (Carmines \& MacIver, 1981); RMR(Root mean square residual) and RMSEA(Root mean square error of approximation) must be under 0.05, and GFI(Goodness of fit), AGFI(Adjust goodness of fit), NFI(normed fit index) and CFI(comparative fit index) must exceed 0.9 (Bagozzi \& Yi, 1988; Joreskog \& Sorbom, 1989). In the overall fit index of the measurement model, $\chi^{2} / \mathrm{df}=2.867$, GFI $=0.961$, AGFI $=0.935, \mathrm{NFI}=0.977, \mathrm{RFI}=0.966, \mathrm{CFI}=0.985$, RMSEA $=0.047$, RMR $=0.045$. Based on the above criteria, our model was shown to have good fitness, indicating strong construct validity and measurement efficiency.

\subsection{Multi-group Competing Model - Comparative Analysis}

We categorized subjects by their travel frequency, which was measured in terms of how often, on average, they visit the Anping District. Subjects who visited Anping every six months or less were categorized as highly frequent (281 subjects); once a year visitors were classified as moderately frequent (272 subjects), and those who visited every 18-24 months fell into the infrequent group (278 subjects).

We employed AMOS statistical software to conduct comparative analysis of these groups, in order to determine whether travel frequency interferes with the variable relationships. The fitness indices of this competitive model are shown in Table 2. Each fitness index met the criteria, being that GFI, AGFI, and NFI $>0.8$ (Forza and Filippini, 1998), CFI > 0.9(Hair et al., 2006), RMSEA < 0.05(Brown and Cudeck, 1933) and $\chi 2 / \mathrm{df} \leqq 3$ (Chau and Hu, 2001), indicating that the model is satisfactory.

According to the $\mathrm{T}$ test results in Table 2, the intensity of the relationship between tourism image and experiential value (H1) was significantly different between the moderately frequent and infrequent groups $(\mathrm{t}=2.443)$ and the highly frequent and infrequent groups $(t=2.427)$. Specifically, image has a greater effect on the experiential value of infrequent visitors, compared to moderately and highly frequent visitors $(0.927>0.86>0.737)$.

The intensity of the relationship between image and satisfaction (H3) was significantly different in the moderately frequent group compared to the infrequent group $(\mathrm{t}=2.135)$. Specifically, image has a greater impact on the satisfaction of infrequent visitors compared to moderately frequent visitors $(0.238>-0.876)$.

The intensity of the relationship between experiential value and satisfaction (H7) was significantly different between the moderately frequent and infrequent groups $(\mathrm{t}=-2.199)$ and the highly frequent and infrequent groups $(\mathrm{t}=-2.217)$. To moderately frequent visitors, experiential value has a more significant effect on satisfaction, compared to highly frequent and infrequent visitors $(1.766>0.876>0.605)$.

The moderately frequent and infrequent groups showed significant difference $(t=-2.184)$ in the relationship between activity appeal and loyalty (H6). The loyalty of moderately frequent visitors is more significantly influenced by how attractive they find the activities, compared to infrequent visitors $(0.169>-0.052)$.

The results above partially support H9. The full results of hypothesis testing are summarized in Table 3 . 
Table 2. The competing model analysis for different travel frequencies groups

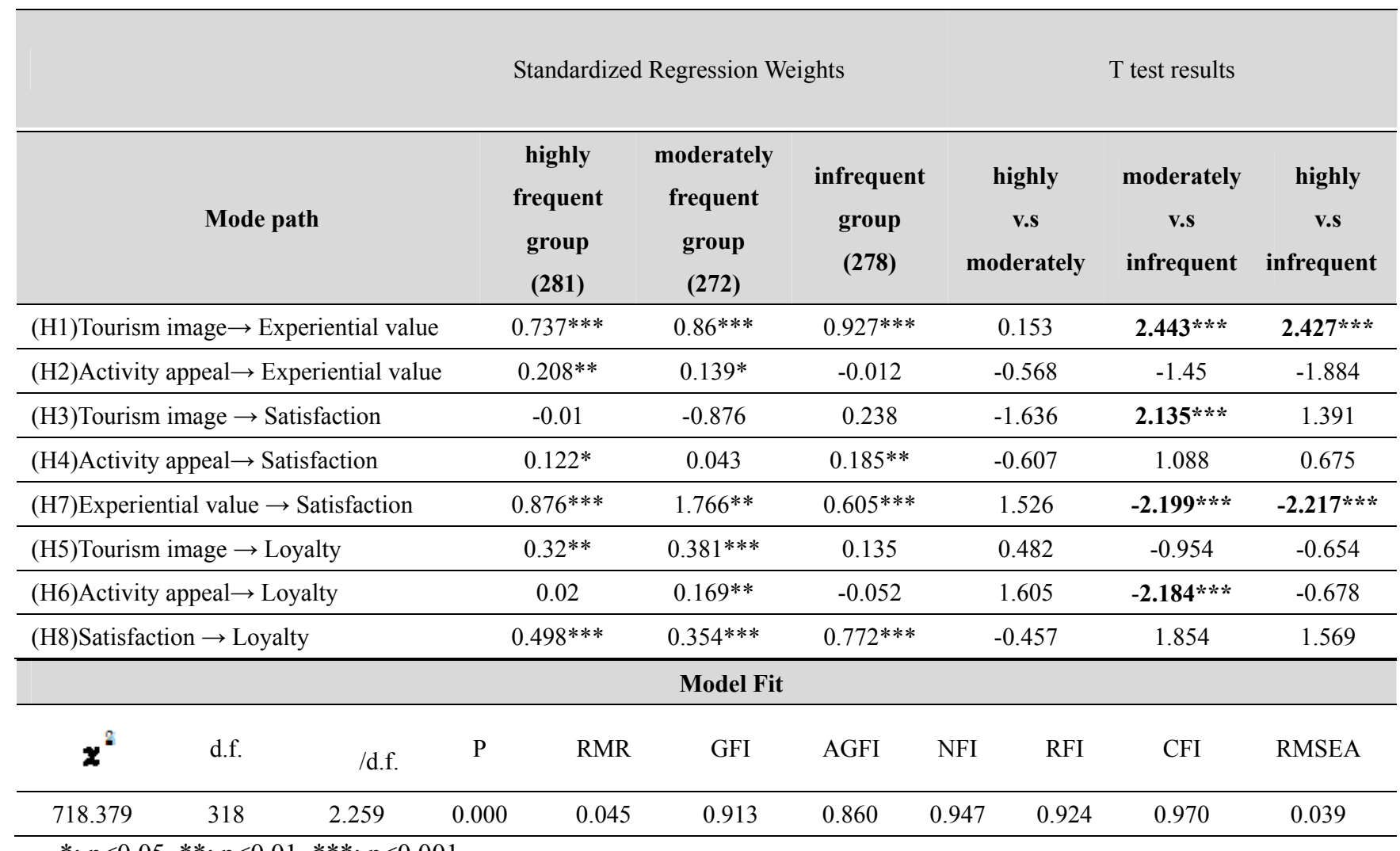

$*: \mathrm{p}<0.05, * *: \mathrm{p}<0.01, * * *: \mathrm{p}<0.001$

Table 3. Research hypothesis testing results

\begin{tabular}{lccc}
\hline \multicolumn{1}{c}{ Research hypotheses } & $\begin{array}{c}\text { highly frequent } \\
\text { H1: Relationship between image and experiential value }\end{array}$ & $\begin{array}{c}\text { moderately } \\
\text { frequent }\end{array}$ & $\begin{array}{c}\text { infrequent } \\
\text { group }\end{array}$ \\
\hline H2: Relationship between activity appeal and experiential value & support & support & support \\
\hline H3: Relationship between image and satisfaction & no support & no support & no support \\
\hline H4: Relationship between activity appeal and satisfaction & support & no support & support \\
\hline H5: Relationship between image and loyalty & support & support & support no support \\
\hline H6: Relationship between activity appeal and loyalty & no support & support & support support \\
\hline H7: Relationship between experiential value and satisfaction & support & support & support \\
\hline H8: Relationship between satisfaction and loyalty & & partially support & support \\
\hline H9: Comparing groups with different travel frequencies & & & nort \\
\hline
\end{tabular}

\section{Conclusions and Recommendations}

\subsection{Conclusions}

We surveyed individuals who had previously visited the Anping District of Tainan City, in order to study the relationships among image, activity appeal, experiential value, satisfaction and loyalty, as well as explore the frequency of visits as an interfering variable. Our results are described below:

1. In all three groups, image was shown to have a positive influence on experiential value, verifying the findings of Bigne et al. (2001) and Fornell et al. (1996). This shows that the more tourists like the image of a destination, the higher their experiential value will be upon visiting and the more inclined they will be to revisit. 
2. Among highly and moderately frequent visitors, the attractiveness of activities was shown to positively influence experiential value, echoing the findings of Leiper(1990) and Hu \& Ritchie(1993). This shows that the attractiveness of the activities offered by a destination affects how tourists feel about their experience there. The more attractive the activities, the higher the experiential value of visitors.

3. Image did not significantly influence satisfaction in any of the groups, which does not support our hypothesis but matches the findings of Bosque \& Martin (2008) and Chen \& Tsai (2007), indicating that image indirectly influences satisfaction through experiential value.

4. In both the highly frequent and infrequent groups, activity appeal was shown to positively influence satisfaction, verifying the results of Ahmad (2012) and Shen \& Hsieh (2003). The more attractive the activities offered by a destination, the more satisfied visitors are with their experience there.

5. Image positively affected the loyalty of both highly and moderately frequent visitors, verifying the findings of Yoon \& Uysal (2005) and Bosque \& Martin (2008). The more positive the image of a place, the more visitors favor it and are inclined to revisit.

6. As discovered by Ahmad (2012) and Shen \& Hsieh (2003), activity appeal positively influenced the loyalty of moderately frequent visitors, indicating that the more attractive the activities offered, the more loyal visitors are to the area.

7. Experiential value positively affected satisfaction in all three groups, echoing the findings of Lee, Lee \& Wicks (2004) and Ross (1993). Tourists who have a better-than-expected experience come away more satisfied with a location. There is a very strong relationship between higher experiential value and increased satisfaction.

8. Satisfaction positively affected loyalty in all three groups, as indicated by Bosque \& Martin, (2008) and Yoon \& Uysal (2005). Visitors who are more satisfied with a tourist destination are more inclined to revisit.

9. We conducted comparative analysis to further understand the differences between groups with different travel frequencies; our findings are as follows:

(1) The influence of image on experiential value is significantly influenced by visiting frequency. According to T-test results, its influence was strongest in the infrequent group, indicating that less frequent visitors place greater emphasis on image, compared to moderately and highly frequent visitors. Tourism organisations in the Anping District should employ effective marketing strategies to highlight its local specialities, attracting less frequent visitors to experience the cultural attributes and sights of the area.

(2) The influence of image on satisfaction is significantly influenced by visiting frequency. According to T-test results, the relationship between image and satisfaction is strongest among infrequent visitors. The Anping District should use effective local marketing strategies to make a positive impression of the area on these visitors.

(3) The influence of experiential value on satisfaction is significantly influenced by visiting frequency. According to T-test results, experiential value has the strongest influence on the satisfaction of moderately frequent visitors. This indicates that the Anping District should work to effectively enhance the quality of the tourist experience, leading moderately frequent visitors to rate the area more highly.

(4) The effect of activity appeal on loyalty is signicantly influenced by visiting frequency. According to T-test results, the attractiveness of activities has the strongest influence on the loyalty of moderately frequent visitors, indicating that tourists in this group place more emphasis on appealing activities, compared to infrequent and highly frequent visitors. Therefore, the Anping District should offer stimulating and unique activities to interest moderately frequent tourists in visiting the area.

\subsection{Implications for Management}

Studying individuals who had visited the Anping District of Tainan City, we explored how destination image and activity appeal affect loyalty through experiential value and satisfaction. We modelled the relationships between each construct and identified valid measurement variables, offering the tourism industry practical research instruments and valuable concepts.

Results showed that the more visitors were attracted to the tourism image and activities of the Anping District, the more loyal they were to the location, through the mediating effects of experiential value and satisfaction. 
Therefore, we recommend that businesses employ marketing strategies to promote the image of the Anping District and the tourist activities offered, raising awareness of its value and encouraging the loyalty of tourists. Businesses should also try to gain a more in-depth understanding of the key factors that influence travellers to Anping, which would assist them in planning relevant activities and devising marketing strategies. For example, local government authorities could promote its natural resources and recreational facilities through the media, as well as host activities to provide tourists with experiential value in the form of enjoyment and relaxation. This would increase the satisfaction of visitors and convey to them the uniqueness of Anping's local culture and image, encouraging greater loyalty to the area.

Experiential value is a key factor of positive influence on the satisfaction of highly frequent visitors; high experiential value increases their satisfaction with and loyalty to a destination. We therefore recommend that frequent tourists be provided with a variety of experiences, quality service, and extensive travel information. Local culture, history and festivals should be incorporated into the itinerary and the area should be promoted through marketing strategies, creating a first-rate destination that will attract tourists.

For moderately frequent and infrequent visitors, tourist image has the most significant effect on their experiential value. Tourism venues and local authorities should emphasize the diversity of recreational activities and quality of service, as well as conserve the rich resources of the area to cultivate a unique image. Activities, service, facilities and dining is strategic to improving the loyalty of these tourist groups.

\subsection{Limitations and Future Recommendations}

A majority of respondents to the survey were aged 15-34 years and resided in the southern and northern regions of Taiwan. Therefore, sampling bias could lead to errors in data analysis. We recommend that future studies employ proportional sampling in distributing questionnaires, in order to increase the accuracy of the research.

Also, different types of tourists place varying degrees of emphasis on image and activity appeal, which could lead to differences in experiential value and satisfaction, and affect the influence of these variables on loyalty. We suggest that future studies categorize and comparatively analyse tourists, applying our relationship models to different tourist groups and exploring the dissimilarities.

\section{References}

Ahmad, AE. M. K. (2012). Attractiveness factors influencing shoppers' satisfaction, loyalty, and word of mouth: An empirical investigation of Saudi Arabia shopping malls. International Journal of Business Administration, 3(6), 101-112. http://dx.doi.org/10.5430/ijba.v3n6p101

Bagozzi, R. P., \& Yi, Y. (1988). On the evaluation of structure equations models. Academic of Marketing Science, 16(1), 76-94.

Baker, K. A., \& Crompton, J. L. (2000). Quality, satisfaction and behavioural intentions. Annals of Tourism Research, 27(3), 785-804.

Baloglu, S., \& McCleary, K. W. (1999). A model of destination image formation. Annals of Tourism Research, 26(4), 808-889.

Bigné, J. E., Sánchez, M. I., \& Sánchez, J. (2001). Tourism image, evaluation, variables, and after purchase behavior: Interrelationship. Tourism Management, 22(6), 607-616. http://dx.doi.org/10.1016/S0261-5177(01)00035-8

Birgit, L. (2001). Image segmentation: The case of a tourism destination. Journal of services marketing, 15(1), 49-66. http://dx.doi.org/abs/10.1108/08876040110381517

Bolton, R. N., \& Drew, J. H. (1991). A longitudinal analysis of the impact of service changes on customer attitudes. Journal of Marketing, 55, 1-9.

Bosque, I. R., \& Martin, H. S. (2008). Tourist satisfaction: A cognitive-affective model. Annals of Tourism Research, $35(2), 551-573$.

Brown, M. W., \& Cudeck, R. (1993). Alternatives ways of assessing model fit. In Bollen, K. A., \& Long, J. S. (Eds.), Testing Structural Equation Model (pp. 136-162). Newbury Park, CA: Sage.

Campo, S., \& Alvarez, M. D. (2014). Can tourism promotions influence a country's negative image? An experimental study on Israel's image. Current Issues in Tourism, 17(3), 201-219.

Carmines, E. G., \& Maclver, J. P. (1981). Analyzing models with unobserved variables. In Bohrnstedt, G. W. \& Borgatta, E. F. (Eds.), Social Measurement: Current Issues (pp. 65-115). CA: Sage Publications. 
Carpenter, M. (2009). Just how joint is joint action in infancy? Topics in Cognitive Science, 1(2), 380-392. http://dx.doi.org/10.1111/j.1756-8765.2009.01026.x

Chau, P. Y. K., \& Hu, P. J. H. (2001). Information technology acceptance by individual professional: A model comparison approach. Decision Sciences, 32(4), 699-719. http://dx.doi.org/10.1111/j.1540-5915.2001.tb00978.x

Chen, C. F., \& Tsai, D. C. (2007). How destination image and evaluative factors affect behavioral intentions? Tourism Management, 28(4), 1115-1122.

Chen, C. F., \& Yuan, S. H. (2006). Alternate Title The Study on Relation Model of Tourists' Behavior at Art Site of Railway Warehouse. Tamsui Oxford Journal of Tourism, (4), 57-78.

Chen, H. C., \& Lee, Y. H. (2006). A study of attraction and revisiting willingness of tourists on Kaohsiung international container arts festival. Journal of Sport and Recreation, 3(1), 74-86.

Court, B., \& Lupton, R. A. (1997). Customer portfolio development: Modeling destination adopters, inactive, and rejecters. Journal of Travel Research, 36(1), 35-43. http://dx.doi.org/10.1177/004728759703600106

Crompton, J. L. (1979a). An assessment of the image of Mexico as a vacation destination and the influence of geographical location upon that image. Journal of Travel Research, 17(4), 18-23. http://dx.doi.org/10.1177/004728757901700404

Cronin, J. J., \& Taylor, S. A. (1992). Measuring service quality: A reexamination and extension. Journal of Marketing, 56(3), 55-68.

Dick, A. S., \& Basu, K. (1994). Customer loyal: toward an integrated conceptual framework. Journal of Academy of marketing Science, 22(2), 99-133.

Dorfman, P. W. (1979). Measurement and meaning of recreation satisfaction: A case study of camping. Environment and Behavior, 11(4), 483-510. http://dx.doi.org/10.1177/0013916579114004

Ennew, C. T., \& Binks, M. R. (1999). Impact of participative service relationships on quality, satisfaction and retention: An exploratory study. Journal of Business Research, 46(2), 121-132.

Fakeye, P. C., \& Crompoton, J. L. (1991). Image differences between prospective, first-time, and repeat visitors to the lower Rio Grande valley. Journal of Travel Research, 30(2), 10-16. http://dx.doi.org/10.1177/004728759103000202

Fornell C (1992). A national customer satisfaction barometer: The Swedish experience. Journal of Marketing, 56(1), 6-21.

Fornell, C., Johnson, M. D., Anderson, E. W., Cha, J., \& Bryant, B. E. (1996). The American customer satisfaction index: Nature, purpose, and findings. Journal of Marketing, 60(4), 7-18.

Forza, C., \& Filippini, R. (1998). TQM impact on quality conformance and customer satisfaction: A causal model. International Journal of Production Economics, 55, 1-20.

Gaski, J. F., \& Nevin, J. R. (1985). The differential effects of exercised and unexercised power sources in a marketing channel. Journal of Marketing Research (JMR), 22(2), 130-142.

Getz, D. (1991). Festivals, special events, and tourism. New York: Van Nostrand Reinhold.

Gunn, C.A. (1988).Tourism Planning (2nd ed.). New York: Taylor \& Frances

Hair, J. F. Jr., Black, W. C., Babin, B. J., Anderson, R. E., \& Tatham, R. L. (2006). Multivariate Data Analysis (6nd ed.). New Jersey: Prentice Hall.

Hu, X., \& Bai, K. (2013). A Study on the tourism destination image restoration scale: A contrast perspective of domestic and inbound tourists integration. Tourism Tribune / Lvyou Xuekan, 28(9), 73-83.

Hu, Y., \& Ritchie, J. R. (1993). Measuring destination attractiveness: A contextual approach. Journal of Travel Research, 32(2), 25-34. http://dx.doi.org/10.1177/004728759303200204

Hunt, J. D. (1975). Image as a factor in tourism development. Journal of Travel Research, 13(13), 1-7. http://dx.doi.org/10.1177/004728757501300301

Joreskog, K. G., \& Sorbom, D. (1989). LISREL 7 Use's Reference Guide. Chicago: Scientific Software.

Kaiser, H. F. (1958). The varimax criterion for analysis rotation in factor analysis. Psychometrika, 23(3), 187-200. Retrieved from http://link.springer.com/article/10.1007\%2FBF02289233 
Kelly, J. R. (1987). Freedom to be-A new sociology of leisure. New York: Macmillan publishing company.

Kerlinger, F. N. (1978). Foundation of Behavioral Research. NY: McGraw-Hill.

Kim, S. H., Holland, S., \& Han, H. S. (2013). A structural model for examining how destination image, perceived value, and service quality affect destination loyalty: A case study of Orlando. International Journal of Tourism Research, 15(4), 313-328.

Ko, P. F., \& Liu, Y. L. (2010). Factor and correlation analyses of tourism attraction, tourist satisfaction and revisiting willingness - evidence from Mainland Chinese tourists to Taiwan. The Business Review Cambridge, 16(2), 255-261.

Kotler, P., Bowen, J., \& Makens, J. (1996). Marketing for hospitality and tourism. New Jersey: Prentice-Hall.

Kozak, M. (2001). Repeaters behavior at two distinct destination. Annals of Tourism Research, 28(3), 784-807.

Lee, C. K., Lee, Y. K., \& Wick, B. E. (2004). Segmentation of festival motivation by nationality and satisfaction. Tourism Management, 25(1), 61-70. http://dx.doi.org/10.1016/S0261-5177(03)00060-8

Lee, J. Graefe, A. R., \& Burns, R. C. (2004). Service quality, satisfaction, and behavioral intention among forest visitors. Journal of Travel \& Tourism Marketing, 17(1), 73-82.

Leiper, Neil. (1990). Tourism Planning: An Integrated and Sustainable Development. New York: Van Nostrand Reinhold.

Leisen, B. (2001). Image segmentation: The case of a tourism destination. Journal of Services Marketing, 15(1), 49-66. http://dx.doi.org/10.1108/08876040110381517

Li, C. J., \& Chen, Y. L. (2009). The research on the relationships among tourism attraction, service quality, perception value, customer satisfaction and loyalty: Using BRAND'S tourism factory as an Example. Journal of Customer Satisfaction, 5(1), 93-120.

Li, L. (2013). Screen-induced tourism: Perceived destination image and intention to visit. Tourism Tribune / Lvyou Xuekan, 28(9), 61-72.

Liu, C. R. (2009). The geography of tourist consumption-a case study on handicrafts selection and loyalty to destination. Hwa kang geographical journal, (23), 85-108.

Liu, Y. L., Tsou, C. T., \& Ting, P.W. (2011). Correlation analyses of travel motivation, preference and revisiting willingness: Evidence from visitors to the Yuan-Tan Ecological Park. Second International Conference on Education and sports Education, Guangzhou, China, 196-199.

Martin, H. S., \& del Bosque, I. A. R. (2008). Exploring the cognitive-affective nature of destination image and the role of psychological factors in its formation. Tourism Management, 29(2), 263-277. http://dx.doi.org/10.1016/j.tourman.2007.03.012

Mayo, E. J., \& Jarvis, L. P. (1981). Psychology of Leisure Travel. Boston: CBI, 191-223.

Mullin, B. (1985). Internal Marketing-A More Effective Way to Sale Sport. In Lewis G. \& Appenzeller (Eds.), Successful sport management. Charlottesville, VA: The Michie Company.

Neirotti, L. D., Bosetti, H. A., \& Teed, K. C. (2001). Motivation to attend the 1996 summer Olympic games. Journal of Travel Research, 39(3), 327-331.

Nunnally, J. C. (1978). Psychometric Theory. NY: Mcgraw-Hill.

Oliver, R. L. (1993). Cognitive, affective, and attribute based of the satisfaction response. Journal of Consumer Research, 20, 418-430.

Oliver, R. L. (1999). Whence consumer loyalty. Journal of Marketing, 63(4), 33-44.

Pearce, P. L. (1982). Perceived changes in holiday destinations. Annals of Tourism Research, 19, 145-164.

Pine, B. J., \& Gilmore, J. H. (1998). Welcome to the experience economy. Harvard Business Review, 76(4), 97-105.

Pine, IT, B. J., \& Gihnore, J. H. (2003). The experience economy. Cite Publishing Ltd.

Reisinger, Y., \& Turner, L. W. (2003). Cross-cultural behaviour in tourism: concepts and analysis. Oxford: Butterworth-Heinemann.

Rittichainuwat, B. N., Qu, H., \& Brown, T. (2001). Thailand's international travel image. Cornell Hotel and Restaurant Administration Quarterly, 42(2), 82-95. 
Ross, G. F. (1993). Destination evaluation and vacation preferences. Annals of Tourism Research, 20(3), 477-489. http://dx.doi.org/10.1016/0160-7383(93)90004-M

Ross, G. F. (1993). Ideal and actual images of backpacker visitors to northern Australia. Journal of Travel Research, 32(2), 54-57. http://dx.doi.org/10.1177/004728759303200208

Royo-Vela, M. (2009). Rural-cultural excursion conceptualization: A local tourism marketing management model based on tourism destination image measurement. Tourism Management. 30(3), 419-428.

Rudež, H. N. (2014). Affective tourism destination image: The case of Portoroz. Trends in Tourism and Hospitality Industry, 3, 245-255.

Schmitt, B. H. (1999). Experiential marketing. Journal of Marketing Management, 15(1), 53-67.

Shen, C. C., \& Hsieh, C. Y. (2003). A study on the relationship among attraction, tourist satisfaction and loyalty of religious tourism-A case of Fo Guang Shan in Kaohsiung. Tourism Management Research, 3(1), 79-95.

Smith, J. B., \& Colgate, M. (2007). Customer value creation: A practical framework. Journal of Marketing Theory and Practice, 15(1), 7-23.

Swarbrooke, J. (2002). The development and management of visitor attractions. London: Butterworth-Heinemann.

Sweeney, J. C., \& Soutar, G. N. (2001). Consumer perceived value: the development of a multiple item scale. Journal of Retailing, 77(2), 203-220.

Tourism Bureau of Tainan City Government. Retrieved October 11, 2012, from http://tour.tainan.gov.tw/

Victor, T. C. (1989). Marketing implications for attractions. Tourism Management, 10(3), 229-232.

Wakefield, K. L., Blodgett, J. G., \& Sloan, H. J. (1996) . Measurement and management of the sportscape. Journal of Sport Management, 10(1), 15-31.

Wang, X., Zhang, J., Gu, C. L., \& Zhen, F. (2009). Examining antecedents and consequences of tourist satisfaction: A structural modeling approach. Tsinghua Science and Technology, 14(3), 397-406.

William, F. T. (1997). Global Tourism: The next decade. London: Butterworth-Heinemann.

Yoon, Y., \& Uysal, M. (2005). An examination of the effects of motivation and satisfaction on destination loyalty: A structural model. Tourism Management, 26(1), 45-56.

Zeithaml, V. A., Berry, L. L., \& Parasuraman, A. (1996). The behavioral consequences of service quality. Journal of Marketing, 60(4), 1-46. 